\title{
The perfusion index of healthy term infants during transition at birth
}

\author{
Jacco K. Kroese $^{1}$ - Jeroen J. van Vonderen ${ }^{1}$ - Ilona C. Narayen ${ }^{1}$ • Frans J. Walther ${ }^{1}$ • \\ Stuart Hooper ${ }^{2}$ - Arjan B. te Pas ${ }^{1}$
}

Received: 14 June 2015 /Revised: 2 October 2015 / Accepted: 5 October 2015 / Published online: 24 October 2015

(C) The Author(s) 2015. This article is published with open access at Springerlink.com

\begin{abstract}
Perfusion index is a continuous parameter provided by pulse oximetry and might be useful for evaluating hemodynamic changes at birth and identifying transitional problems. The objective was to describe perfusion index values in term infants immediately after birth. Perfusion index of 71 healthy term born infants were recorded during the first 10 min after birth, using a pulse oximetry sensor placed preductally. A Wilcoxon signed-rank test was used to compare between time points. No significant trend in perfusion index could be observed in term-delivered infants. There was a significant difference between 2 and $3 \mathrm{~min}(2.4$ (1.6-5.0) vs. 2.3 (1.6-3.7), $p=0.05)$ and between 3 and 4 min after birth (2.3 $(1.6-3.7)$ vs. $2.1(1.4-3.2), p<0.001)$. There was no significant change in median PI values in the following $8 \mathrm{~min}$.
\end{abstract}

Communicated by Patrick Van Reempts

Jeroen J. van Vonderen

j.j.van_vonderen@lumc.nl

Jacco K. Kroese

jkkroese@gmail.com

Ilona C. Narayen

i.c.narayen@lumc.nl

Frans J. Walther

f.j.walther@lumc.nl

Stuart Hooper

stuart.hooper@monash.edu.au

Arjan B. te Pas

a.b.te pas@lumc.nl

1 Department of Pediatrics, Division of Neonatology, Leiden University Medical Center, J6-S, PO Box 9600, 2300

RC Leiden, The Netherlands

2 MIMR-PHI Institute for Medical Research, Monash University, Clayton, Victoria, Australia
Conclusion: Perfusion index does not change significantly during transition at birth in healthy term infants born by normal vaginal delivery or cesarean section. Large variation in perfusion index causes monitoring this parameter to have limited value.

\section{What is known:}

- Perfusion index is a non-invasive indicator for peripheral perfusion.

- Perfusion index values $<1.24$ are seen as an accurate predictor for severity of illness for infants admitted to the neonatal intensive care unit.

What is new:

- Although significant physiological changes occur during birth, perfusion index remains stable.

- Large variation in perfusion index causes monitoring of this value to have limited value as an additional parameter for evaluating transition at birth.

Keywords Neonatal transition · Newborn · Perfusion index · Heart rate $\cdot$ Oxygen saturation
Abbreviations
HR Heart rate
PI Perfusion index
$\mathrm{PO}$ Pulse oximetry
$\mathrm{SpO}_{2} \quad$ Oxygen saturation

\section{Introduction}

In recent years, pulse oximetry $(\mathrm{PO})$ has been recognized as an easily applicable, non-invasive monitoring tool and is now routinely used in the delivery room to monitor transition at birth $[5,15,22,24]$. PO is recommended for objective evaluation 
of heart rate (HR) and oxygen saturation $\left(\mathrm{SpO}_{2}\right)$ at birth $[5$, 26], and it is used to decide if interventions are necessary [16, 20, 31]. In addition to $\mathrm{HR}$ and $\mathrm{SpO}_{2}$, the infrared signal of a $\mathrm{PO}$ can also be used to determine the perfusion index (PI). PI is calculated as the ratio of the pulsatile signal (arterial blood flow) indexed against the non-pulsatile signal (static blood flow, skin, and other tissues) and is a non-invasive indicator for peripheral perfusion [17]. PI has been related to the flow through the superior vena cava in preterm infants [28] and volume responsiveness in neonates [2]. Moreover, low PI values $(<1.24)$ has been identified as an indicator for severe illness in newborn infants $[10,12]$.

During neonatal transition, significant respiratory and hemodynamic changes occur, influencing cardiac output as well as systemic and peripheral perfusion [3, 4, 19, 25]. Currently, only $\mathrm{SpO}_{2}$ and HR are used for clinical evaluation, but these parameters do not reflect the complete hemodynamic status of the infant at birth [30]. Tissue perfusion is not only dependent on HR but also stroke volume and blood pressure [29]. Continuous monitoring of the perfusion by means of PI measurements could be valuable for evaluation of newborn infants during neonatal transition as large changes take place during the neonatal transition. Although PI values have been described in term infants during neonatal transition $[9,14]$ and the first days after birth $[1,12,13]$, PI values obtained immediately after birth have not yet been reported. The objective of this study was to evaluate and to establish reference values for PI of healthy term-born infants during the first $10 \mathrm{~min}$ after birth.

\section{Methods}

We analyzed PO recordings of healthy term infants born via uncomplicated vaginal delivery or elective cesarean section who did not need medical support. The study was approved by the LUMC institutional review board and the parents were approached before birth for informed consent. Recordings of term infants born between February 2012 and March 2013 were reviewed retrospectively. Gestational age was determined by performing an antenatal ultrasound, which is standard of care in the Netherlands. Recordings were included if PI measurements were obtained shortly after birth and time of birth was indicated. Recordings were excluded if infants received respiratory support.

Directly after birth, the infant was placed under a radiant warmer. PI, HR, and $\mathrm{SpO}_{2}$ were recorded by one member of the research team. During each delivery, a pediatric resident, a neonatal IC nurse, and one researcher were present. The researcher $(\mathrm{JV})$ put the PO sensor on. The PO sensor (M-LNCS NeoPt-500, Masimo SET, Masimo, Irvine, CA, USA) was always placed on the ulnar aspect of the right wrist providing preductal arterial values [20] and connected to a pulse oximeter (Masimo Radical 7, Masimo, Irvine, CA, USA) [21]. PI, HR and $\mathrm{SpO}_{2}$ were recorded at maximum sensitivity every $2 \mathrm{~s}$ from 2 min after birth until 10 min after birth or earlier if the infant was placed in the transport incubator. The recorded values were collected using the Spectra Physiological Recording Program (Grove Medical, London, UK) and stored on a laptop. Data were averaged for each infant at each $60 \mathrm{~s}$ interval, comprising of the data points of $10 \mathrm{~s}$ of data before and after each $60 \mathrm{~s}$ interval. Data were considered valid for analysis if PI, HR, and $\mathrm{SpO}_{2}$ were simultaneously present at a time point and the plethysmography pulse wave was confirmed to be artifact free. Limits of PI values identified to be unvalid were $\leq 0.02$ and $\geq 20$ and simultaneous absence of $\mathrm{HR}$ and $\mathrm{SpO}_{2}$ values [18].

\section{Statistical analysis}

Data were analyzed using SPSS 20.0 for Windows (IBM, Chicago, IL, USA). All variables were tested for normality using the Kolmogorov-Smirnov test. Data were presented as mean (SD) or median (IQR), where appropriate. For nonnormally distributed data, a Wilcoxon signed-rank test was used to compare PI between time points within groups. To account for multiple comparisons between the time points, tests were performed using the Bonferroni corrected level $(p=0.05 / 2=0.025)$. A (two-sided) $p$ value of $<0.05$ was considered as statistically significant.

\section{Results}

PO values of 71 infants with a mean (SD) gestational age of 40 (1) weeks and a birth weight of 3575 (482) grams were recorded and analyzed. Thirty-nine infants were born after cesarean section and 32 infants were born after vaginal delivery. Median (IQR) Apgar score was 9 (9-9) at $1 \mathrm{~min}$ and 10 (10$10)$ at $5 \mathrm{~min} .97 \%$ of data (5860 data points) of the PI measurements were of good quality and were included.

The median time (IQR) taken to acquire PI, $\mathrm{HR}$, and $\mathrm{SpO}_{2}$ simultaneously was $110 \mathrm{~s}(110-126 \mathrm{~s})$. $\mathrm{HR}$ and $\mathrm{SpO}_{2}$ were within ranges described by Dawson et al. (Table 1) $[6,8]$. The median PI over the first 10 min was 2.1 (1.4-3.5). There was no significant difference between infants born by cesarean section or after vaginal delivery. There was a significant difference between 2 and $3 \mathrm{~min}(2.4(1.6-5.0)$ vs. $2.3(1.6-3.7)$, $\mathrm{p}=0.05)$ and between 3 and 4 min after birth (2.3 (1.6-3.7) vs. $2.1(1.4-3.2), p<0.001)$. There was no significant change in median PI values in the following 8 min (Fig. 1).

\section{Discussion}

This is the first study reporting the course of PI of healthy term infants during transition at birth. Significant physiological changes occur during transition and although this is reflected 
Table 1 Perfusion index, heart rate, and oxygen saturation measurements (median (IQR)) of healthy term infants during the first $10 \mathrm{~min}$ after birth

\begin{tabular}{lllll}
\hline Time (min) & $N$ & $\mathrm{PI}(\%)$ & $\mathrm{HR}(\mathrm{bpm})$ & $\mathrm{SpO}_{2}(\%)$ \\
\hline 2 & 54 & $2.4(1.6-5.0)$ & $132(64-165)$ & $82(73-90)$ \\
3 & 62 & $2.3(1.6-3.7)$ & $147(105-165)$ & $85(76-91)$ \\
4 & 62 & $2.1(1.4-3.2)$ & $145(124-157)$ & $85(80-91)$ \\
5 & 64 & $2.0(1.4-3.5)$ & $141(128-151)$ & $88(79-93)$ \\
6 & 65 & $2.3(1.4-3.8)$ & $144(124-154)$ & $89(82-93)$ \\
7 & 68 & $2.0(1.3-3.9)$ & $144(126-156)$ & $90(86-94)$ \\
8 & 69 & $2.0(1.4-3.1)$ & $142(125-156)$ & $92(87-95)$ \\
9 & 69 & $2.0(1.3-3.2)$ & $142(129-152)$ & $92(88-96)$ \\
10 & 61 & $2.0(1.4-3.1)$ & $144(133-151)$ & $93(89-96)$
\end{tabular}

$\mathrm{PI}$ perfusion index, $\mathrm{HR}$ heart rate, $\mathrm{SpO}_{2}$ oxygen saturation

by changes in $\mathrm{SpO}_{2}$ and $\mathrm{HR}$, we observed that PI decreases significantly during between 2 and 4 min after birth, after which remains stable, and no trend could be observed. Currently, the only non-invasive monitoring used in the delivery room is the measurement of heart rate. This does not reflect the complete hemodynamic status of the infant at birth [30]. PI could be of added value; however, the large variation in PI causes monitoring of PI to have limited value as an additional parameter for evaluating transition at birth.

Hawkes et al. found a moderate correlation with HR and found no significant correlation for PI with blood pressure values, lactate levels, and gestational age. Furthermore, no trend was observed during the first $10 \mathrm{~min}$ of life [14].
The observed PI is similar to a previous study by de Felice et al., reporting no differences in PI values measured at $0-1 \mathrm{~min}$ and $1-5$ min after birth [9]. This could indicate that pulsed waveforms measured in preductal arteries remain stable despite the large hemodynamic changes that occur during transition. All infants cried and most likely aerated their lungs in the first breaths after birth before the cord was clamped. It has been shown that breathing before cord clamping leads to more stable changes in cardiac output during transition, which could have influenced the measured PI [19, 27]. After cord clamping, systemic vascular resistance increases when the lungs are aerated and pulmonary vascular resistance decreases, which causes a left-to-right ductal shunt [4]. This could have mitigated changes in peripheral circulation, and is in line with our previous observation that peripheral blood pressure remains stable during transition [30]. More studies on circulation in the extremities would be needed to confirm or refute this.

We measured a lower preductal PI at 5 min after birth than de Felice et al. measured postductally in healthy term infants (4.4 (2.1) vs. $2.0(1.4-3.5))$ [9]. This difference is difficult to explain, as we expect postductal perfusion to be maintained secondary to an increase in left-to-right ductus arteriosus shunting [32]. However, as PI is a scaled numerical value derived from the magnitude of the pulsations, it is possible that a ductal steal (increase in left-to-right shunt in the ductus arteriosus) might lead to larger pulse waveforms postductally, resulting from a lower end-diastolic pressure. This is similar to the presence of bounding pulses as a clinical sign for a patent ductus arteriosus.

De Felice et al. suggested PI values $<1.24$ as an accurate predictor for severity of illness [9]. Although we have not

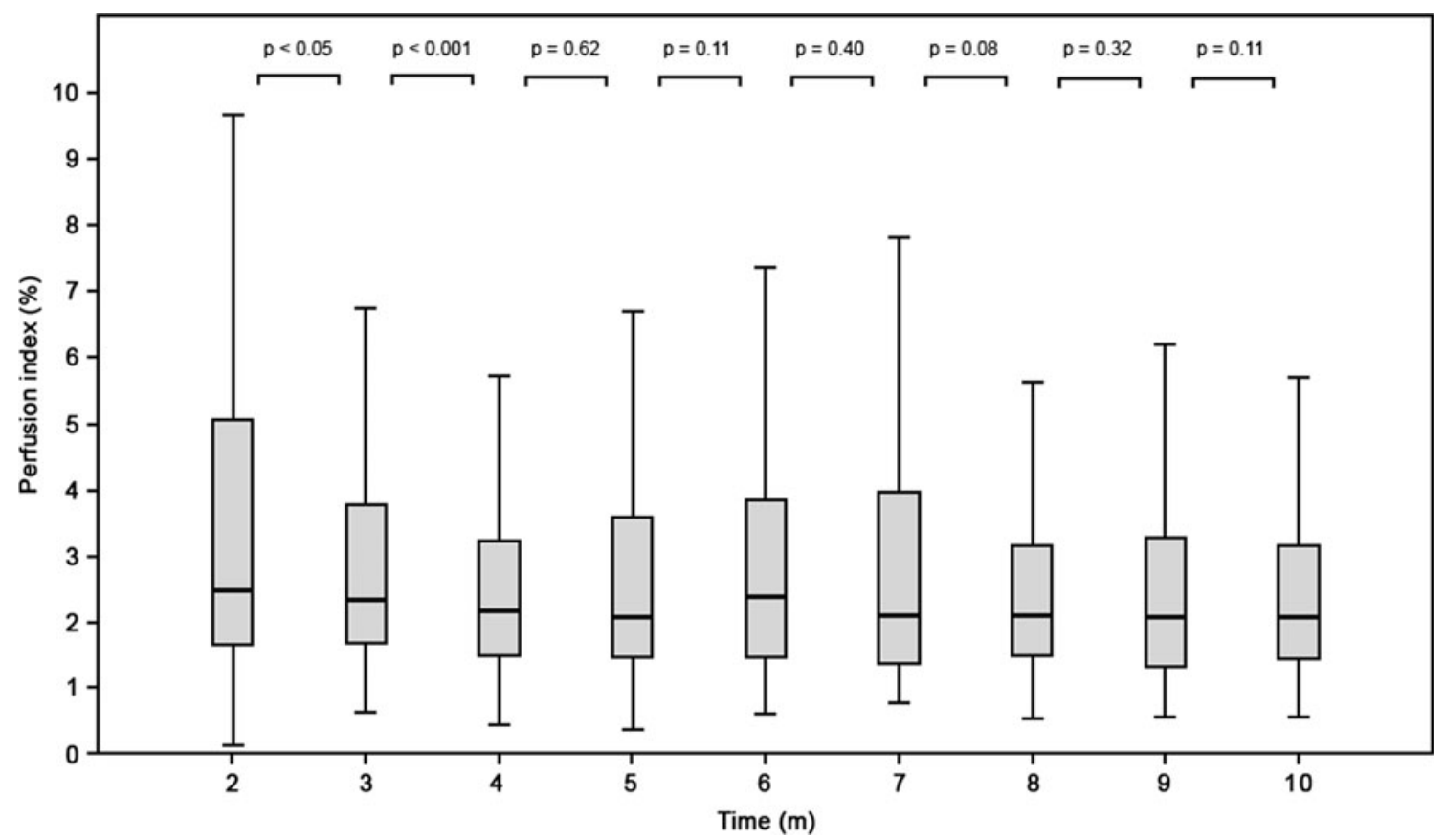

Fig. 1 Median (IQR) of perfusion index (PI) values of healthy term born term infants during the first 10 min of life 
compared the values of the healthy term cohort with sick infants at birth, we cannot confirm this cutoff value as approximately $25 \%$ of our healthy term infants had a PI $<1.24$, and none of these infants needed medical support or were admitted for medical care later on. Also, approximately $25 \%$ of the infants had a PI above 3.5 during the same time points. This difference could be explained by various individual differences such as local vasodilatation and vasoconstriction [7].

The nature of this study was retrospective. We intended to provide PI values for healthy infants during the first minutes after birth and infants that needed medical support were excluded. Therefore, this did not influence our findings. A limitation of our study is the performance of the PO which could explain the wide range in PI observed during transition [11]. Whether some of this variability might be device- specific remains unclear, as no studies have yet been performed comparing PI using different PO monitors [23]. In addition, PI varies between individuals reflecting changes in the physiologic state at the measurement site [7]. Although we did not find a clear trend as there was large variability, comparable to $\mathrm{HR}$ and $\mathrm{SpO}_{2}$, a continuous monitoring could give the caregiver more information than a single value. Although we reported values of healthy term infants, comparison with term infants with transitional problems is needed to determine whether the PI is a useful parameter for hemodynamic evaluation of transition and clinical decision making.

In conclusion, we reported PI measurements in healthy term infants during the first $10 \mathrm{~min}$ after birth. There was a small but significant decrease in PI during the first $4 \mathrm{~min}$, after which PI remained equal and variability was high healthy term born infants.

Acknowledgments S.B. Hooper received a NHMRC research fellowship 545921 .

Author's contributions Jacco K. Kroese carried out the initial analyses, drafted the initial manuscript, and approved the final manuscript as submitted. Jeroen J. van Vonderen performed the data collection, drafted the initial manuscript, and approved the final manuscript as submitted. Stuart B. Hooper, Frans J. Walther, and Ilona C. Narayen reviewed and revised the manuscript, and approved the final manuscript as submitted. Arjan B. te Pas conceptualized and designed the study, supervised the data collection, reviewed, and revised the manuscript, and approved the final manuscript as submitted.

\section{Compliance with Ethical Standards}

Conflict of interest The authors declare that they have no competing interests.

Open Access This article is distributed under the terms of the Creative Commons Attribution 4.0 International License (http://creativecommons.org/licenses/by/4.0/), which permits unrestricted use, distribution, and reproduction in any medium, provided you give appropriate credit to the original author(s) and the source, provide a link to the Creative Commons license, and indicate if changes were made.

\section{References}

1. Alderliesten T, Lemmers PM, Baerts W, Groenendaal F, van Bel F (2015) Perfusion index in preterm infants during the first 3 days of life: reference values and relation with clinical variables. Neonatology 107:258-265

2. Bagci S, Müller N, Müller A, Heydweiller A, Bartmann P, Franz A (2013) A pilot study of the pleth variability index as an indicator of volume-responsive hypotension in newborn infants during surgery. J Anesth 27:192-198

3. Bhatt S, Alison BJ, Wallace EM, Crossley KJ, Gill AW, Kluckow M, te Pas AB, Morley CJ, Polglase GR, Hooper SB (2013) Delaying cord clamping until ventilation onset improves cardiovascular function at birth in preterm lambs. J Physiol 591:2113-2126

4. Crossley KJ, Allison BJ, Polglase GR, Morley CJ, Davis PG, Hooper SB (2009) Dynamic changes in the direction of blood flow through the ductus arteriosus at birth. J Physiol 587:4695-4704

5. Dawson JA, Davis PG, O'Donnell CPF, Kamlin CO, Morley CJ (2007) Pulse oximetry for monitoring infants in the delivery room: a review. Arch Dis Child Fetal Neonatal Ed 92:F4-F7

6. Dawson JA, Kamlin CO, Vento M, Wong C, Cole TJ, Donath SM, Hooper SB, Davis PG, Morley CJ (2010) Defining the reference range for oxygen saturation for infants after birth. Pediatrics 125 : e1340-e1347

7. Dawson JA, Kamlin CO, Wong C, te Pas AB, O'Donnell CPF, Donath SM, Davis PG, Morley CJ (2009) Oxygen saturation and heart rate during delivery room resuscitation of infants $<30$ weeks' gestation with air or $100 \%$ oxygen. Arch Dis Child Fetal Neonatal Ed 94:F87-F91

8. Dawson JA, Kamlin CO, Wong C, Te Pas AB, Vento M, Cole TJ et al (2010) Changes in heart rate in the first minutes after birth. Arch Dis Child Fetal Neonatal Ed 95:F177-F181

9. De Felice C, Del Vecchio A, Criscuolo M, Lozupone A, Parrini S, Latini G (2005) Early postnatal changes in the perfusion index in term newborns with subclinical chorioamnionitis. Arch Dis Child Fetal Neonatal Ed 90:F411-F414

10. De Felice C, Latini G, Vacca P, Kopotic RJ (2002) The pulse oximeter perfusion index as a predictor for high illness severity in neonates. Eur J Pediatr 161:561-562

11. Fouzas S, Priftis KN, Anthracopoulos MB (2011) Pulse oximetry in pediatric practice. Pediatrics 128:740-752

12. Granelli A, Ostman-Smith I (2007) Noninvasive peripheral perfusion index as a possible tool for screening for critical left heart obstruction. Acta Paediatr 296:1455-1459

13. Hakan N, Dilli D, Zenciroglu A, Aydin M, Okumus N (2014) Reference values of perfusion indices in hemodynamically stable newborns during the early neonatal period. Eur J Pediatr 173:597602

14. Hawkes GA, O’Toole JM, Kenosi M, Ryan CA, Dempsey EM (2015) Perfusion index in the preterm infant immediately after birth. Early Hum Dev 91:463-465

15. Kamlin CO, O’Donnell CPF, Davis PG, Morley CJ (2006) Oxygen saturation in healthy infants immediately after birth. J Pediatr 148 : 585-589

16. Kopotic RJ, Lindner W (2002) Assessing high-risk infants in the delivery room with pulse oximetry. Anesth Analg 94:S31-S36

17. Lima AP, Beelen P, Bakker J (2002) Use of a peripheral perfusion index derived from the pulse oximetry signal as a noninvasive indicator of perfusion. Crit Care Med 30:1210-1213

18. Masimo Corporation (2004) Radical signal extraction pulse oximeter operator's manual. 2004. Irvine, Masimo. 13

19. Meyer MP, Mildenhall L (2012) Delayed cord clamping and blood flow in the superior vena cava in preterm infants: an 
observational study. Arch Dis Child Fetal Neonatal Ed 97: F484-F486

20. O’Donnell CPF, Kamlin CO, Davis PG, Morley CJ (2005) Obtaining pulse oximetry data in neonates: a randomised crossover study of sensor application techniques. Arch Dis Child Fetal Neonatal Ed 90:F84-F85

21. O’Donnell CPF, Kamlin CO, Davis PG, Morley CJ (2005) Feasibility of and delay in obtaining pulse oximetry during neonatal resuscitation. J Pediatr 147:698-699

22. Perlman JM, Wyllie J, Kattwinkel J, Atkins DL, Chameides L, Goldsmith JP, Guinsburg R, Hazinski MF, Morley C, Richmond S, Simon WM, Singhal N, Szyld E, Tamura M, Velaphi S (2010) Part 11: neonatal resuscitation: 2010 international consensus on cardiopulmonary resuscitation and emergency cardiovascular care science with treatment recommendations. Circulation 122:S516-S538

23. Piasek CZ, Van Bel F, Sola A (2014) Perfusion index in newborn infants: a noninvasive tool for neonatal monitoring. Acta Paediatr 103:468-473

24. Prasad S, Watcher D, Aitchison R, Aitchison P, Wang E, Kharasch M (2013) Neonatal resuscitation guidelines. Dis Month 59:196-201

25. Richardson BS, Carmichael L, Homan J, Johnston L, Gagnon R (1996) Fetal cerebral, circulatory, and metabolic responses during heart rate decelerations with umbilical cord compression. Am J Obstet Gynecol 175:929-936
26. Singh JK, Kamlin CO, Morley CJ, O’Donnell CPF, Donath SM, Davis PG (2008) Accuracy of pulse oximetry in assessing heart rate of infants in the neonatal intensive care unit. J Paediatr Child Health 44:273-275

27. Sommers R, Stonestreet BS, Oh W, Laptook A, Yanowitz TD, Raker C, Mercer J (2012) Hemodynamic effects of delayed cord clamping in premature infants. Pediatrics 129:e667-e672

28. Takahashi S, Kakiuchi S, Nanba Y, Tsukamoto K, Nakamura T, Ito Y (2010) The perfusion index derived from a pulse oximeter for predicting low superior vena cava flow in very low birth weight infants. J Perinatol 30:265-269

29. Teitel DF, Iwamoto HS, Rudolph AM (1987) Effects of birth-related events on central blood flow patterns. Pediatr Res 22:557-566

30. van Vonderen JJ, Roest AA, Siew ML, Blom NA, van Lith JM, Walther FJ, Hooper SB, te Pas AB (2014) Noninvasive measurements of hemodynamic transition directly after birth. Pediatr Res 75:448-452

31. Vento M, Aguar M, Leone TA, Finer NN, Gimeno A, Rich W, Saenz P, Escrig R, Brugada M (2008) Using intensive care technology in the delivery room: a new concept for the resuscitation of extremely preterm neonates. Pediatrics 122:1113-1116

32. Vidal M, Ferragu F, Durand S, Baleine J, Batista-Novais AR, Cambonie G (2013) Perfusion index and its dynamic changes in preterm neonates with patent ductus arteriosus. Acta Paediatr 102:373 